\title{
RESEARCH
}

\section{Assessing Pharmacy Students' Scientific Reasoning After Completing a Physics Course Taught Using Active-Learning Methods}

\author{
Mirko Marušić, $\mathrm{PhD}^{\mathrm{a}}$, Ante Dragojević ${ }^{\mathrm{b}}$ \\ ${ }^{a}$ University of Split, Department of Physics, Faculty of Chemistry and Technology, Split, Croatia \\ ${ }^{\mathrm{b}}$ University of Zagreb, School of Medicine, Zagreb, Croatia
}

Submitted March 21, 2019; accepted February 3, 2020; published August 2020.

Objective. To assess the degree of change in the level of scientific reasoning in first-year pharmacy students by applying active-learning methods during a physics course.

Methods. The efficiency of the active-learning methods of experimentation and discussion in the development of scientific reasoning in 90 pharmacy students was determined by comparing it to the efficiency of using traditional learning methods (eg, lecture) with 60 students. The Lawson Classroom Test of Scientific Reasoning was used to measure change.

Results. The data from this five-year study showed that of all pharmacy students in the active-learning group who were functioning on a stable or transitional level of thinking at the time of the pretest, $28.6 \%$ achieved a shift towards a higher level of scientific thinking. The active-learning group also achieved better overall results in the course.

Conclusion. Using active-learning methods (experimentation and discussion) in a physics course enabled pharmacy students to better master the content. By elevating students' level of scientific reasoning, a foundation for using evidence-based medicine was established.

Keywords: physics for pharmacy, active learning, experimenting and discussion, change the level of scientific thinking

\section{INTRODUCTION}

At the heart of all evidence-based knowledge is scientific reasoning. From the perspective of scientific literacy, scientific thinking refers to a set of cognitive skills required for understanding and evaluating scientific information, often involving the understanding and assessment of theoretical, statistical, and causal hypotheses. ${ }^{1}$

By shifting from a focus on classical scientific experimentation to a focus on socially constructed scientific knowledge, the conceptual framework of scientific thinking has expanded. This view of scientific thinking emphasizes the importance of assessing and coordinating evidence to improve scientific knowledge. ${ }^{2}$

In her framework for the study of the development of scientific reasoning, Zimmerman states that scientific thinking includes "the thinking and reasoning skills that support the formation and modification of concepts about the natural and social world." ${ }^{3}$ Furthermore, Stevens states that scientific reasoning consists of skills involved in inquiry, experimentation, evidence evaluation, and inference that can lead to conceptual change or scientific

Corresponding Author: Mirko Marušić, University of Split, Department of Physics, Split, Croatia. Tel: 0038521329450. Email: mmarusic@ktf-split.hr. understanding. ${ }^{4}$ Some philosophers emphasize the importance of paradigms ${ }^{5}$ and research programs in science. ${ }^{6}$ This orientation towards science accepts traditional hypotheticodeductive methods and experimental evidence, but also attaches importance to the collective application and confirmation of such evidence as reflected in shifts in paradigms and research programs. For many students, the degree to which they understand basic scientific concepts depends on the degree of scientific reasoning they have achieved. ${ }^{7,8} \mathrm{~A}$ scientific education should improve students scientific reasoning skills and understanding of basic scientific concepts. Many studies point to a significant link between advanced thinking skills and better conceptual understanding. ${ }^{9-11}$

According to Piaget's model of cognitive development, an individual progresses through discrete phases and, with time, develops the ability of scientific reasoning. ${ }^{12}$ Students go through different phases of development until they reach the highest level of scientific reasoning: the formal operational stage. At that point, they can isolate and control variables within the observed problem and observe their interrelationships. ${ }^{13}$

Research has shown that a large number of high school and university students have not yet reached the formal operational stage of thinking. ${ }^{14,15}$ Arons and 


\section{American Journal of Pharmaceutical Education 2020; 84 (8) Article 7610.}

Karplus found that only one third of the US population in the age range of 13 to 15 years have reached the formal operational stage of reasoning. ${ }^{16}$ Most are limited to a concrete operational stage or the transitional stage, ie, the individual is only partly capable of formal operational reasoning. Maloney showed that in the calculus- and algebra-based physics courses for science majors at Creighton University, two thirds of students reached the level of formal operations; however, in courses for students majoring in education or the health sciences, only about one third of students reached that level. ${ }^{17}$ On the other hand, extensive research carried out on a representative sample of 10,000 students between the ages of 10 and 16 years showed that the development of early formal thinking is confined to the top $20 \%$. Moreover, the data also indicated that most of their development had already taken place by the age of 14.5 years. ${ }^{18}$

Discussions about the ways in which scientists develop their thinking skills, defend their conclusions, and deal with alternative explanations are frequently missing in science classrooms. Many science instructors presume that their courses will advance students' scientific reasoning without students' active and personal participation in the scientific process. ${ }^{19}$ Such instructors purpose that that lecturing students on scientific facts and concepts or subjecting them to rote manipulation of laboratory apparatus will alone advance their scientific reasoning. However, those same instructors may be surprised when students encounter difficulties writing laboratory reports or applying their acquired knowledge to new experimental situations.

One of the specific approaches to research on scientific thinking is focusing on the development of this cognitive ability during medical education. Because of the recent emphasis on evidence-based medicine, the development of scientific thinking has become a necessary goal to be achieved during medical education. ${ }^{20}$ Access to patient-centered clinical practice and the "paradigm of best evidence" has had an impact on academic content, teaching methods, and the curricular structure of medical education. ${ }^{20}$ Evidenced-based medicine (EBM) is an approach that involves applying systematic findings and critical review of the latest scientific findings to everyday clinical work. Practicing EBM involves applying the following four steps: define a clear clinical issue based on the problem; systematically search the literature to find relevant scientific knowledge; critically review the evidence found with regard to its validity and applicability; and select a strategy that is valid and applicable in a given situation. These steps inherently characterize a high degree of scientific thinking. The development of scientific thinking in medical education can be traced through two branches of thought: cognitive learning theories (focused on individual cognitive processes) and constructivist learning theories (focused on interaction within the educational environment). Both perspectives provide valuable support for the design and implementation of educational methods applied in medicine. ${ }^{21}$ Based on these findings, the medical curriculum has integrated academic content, teaching methods, and structure of the curriculum to suit the needs of students. Research involving pedagogy within medicine has revealed two main types of medical curriculum: conventional learning and problem-based learning. ${ }^{21}$

Active learning is the main feature of modern education in health professions education. ${ }^{22}$ As insufficient cognitive development is a limiting factor in understanding scientific concepts, it makes sense to conduct research aimed at changing that state. In this study, we explored if and how active problem-based learning increases the level of scientific thinking among pharmacy students. Our main research objective was to determine how using active-learning methods to teach a physics course affected gains in pharmacy students' level of scientific reasoning.

\section{METHODS}

The study included 150 first-year students and was conducted during the Physics for Pharmacists course at the Faculty of Chemistry and Technology, University of Split, Republic of Croatia. Only two students decided to stop studying before completing the course, and they are not included in the research (Table 1). The Physics for Pharmacists course consists of lectures, seminars, and laboratory exercises. During this research, all the students had an identical syllabus (regarding duration, instructors, and topics). In the academic years 2013-2014, 2014-2015, and 2015-2016, we reduced the duration of lecturing part during laboratory exercises for 90 students in the activelearning group and created a 30-minute time span in which we added the active-learning methods through experimentation and discussion. In academic years 20162017 and 2017-2018, the 60 students in the control group attended regular full-time laboratory exercises (traditional methods group). Therefore, during the first three years of the study, students used the active-learning methods of experimentation and discussion (activelearning group) and during the last two years of the study students did not use active-learning methods (traditional methods group). At the end of the course, both the active-learning and traditional learning groups covered the same topics and had the same total duration of these sessions. 


\section{American Journal of Pharmaceutical Education 2020; 84 (8) Article 7610.}

Table 1. Comparison of Pharmacy Students Assigned to Active-Learning and Traditional Learning Groups as Part of a Research Study to Encourage the Development of Scientific Reasoning

\begin{tabular}{|c|c|c|c|c|c|c|c|c|}
\hline & & \multicolumn{4}{|c|}{$\begin{array}{l}\text { Active-Learning } \\
\text { Methods Group }\end{array}$} & \multicolumn{3}{|c|}{$\begin{array}{l}\text { Traditional Learning } \\
\text { Methods Group }\end{array}$} \\
\hline & & 2013-2014 & 2014-2015 & 2015-2016 & $\Sigma$ & 2016-2017 & $2017-2018$ & $\Sigma$ \\
\hline \multirow[t]{2}{*}{ Students, No. } & Pretest & 30 & 31 & 31 & 92 & 30 & 30 & 60 \\
\hline & Posttest & 29 & 30 & 31 & 90 & 30 & 30 & 60 \\
\hline Average age on the LCSTR pretest, $y$ & & 19.1 & 18.9 & 19.3 & $19.1^{\mathrm{a}}$ & 19.4 & 19.1 & 19.3 \\
\hline
\end{tabular}

${ }^{a}$ Statistically no different than traditional learning method group, $p>.05$

The rating system in the Republic of Croatia uses grades 1 to 5 , with 5 being the highest possible grade. To successfully complete Physics for Pharmacists, students are required to pass the written and oral parts of the final test. When assessing students, both the oral and the written examination are taken into account. The authors did not participate in the student evaluation.

Learning physics through experimentation and discussion is a teaching method that combines Piaget's idea of cognitive conflict as the main driver of cognitive development with Vygotsky's emphasis on collective learning. In this process, we used a new learning approach in which students were active participants in the process of construction and reconstruction of their own knowledge. An essential element of active learning is the use of sequence, ie, predict, observe, explain, ${ }^{23}$ or observe, explain, predict, test. ${ }^{24}$ These sequences activate students' prior knowledge and put it to the test by comparing the predicted and noticed. The sequences of active learning are implemented using simple experiments involving the physical phenomena on which students have well-known "alternative conceptions" ${ }^{12}$ : force and the concept of movement; pressure (hydrostatic, hydraulic, atmospheric, hydrodynamic); heat; and sound waves.

To test our active-learning process, we divided 90 students into nine small groups of 10 students. Figure 1 shows the cycle of active learning of physics using simple experiments for one group (Appendix 1). After the group completed laboratory exercises defined by the curriculum, a simple experiment was described to a group but without executing it. Students were asked to predict the possible outcome of the experiment, to offer an explanation of the expected results, and finally, to share their ideas with the group. Once the group defined all the possible outcomes of the experiment, students engaged in a discussion and attempted to explain why they expected such outcomes. The discussion allowed both the instructor and the students to recognize the problem of students' alternative preconceptions as well as their level of scientific reasoning. After the discussion, the experiment was conducted by the instructor and the students observed and recorded the outcome. Surprising outcomes commonly elicited enjoyment and positive emotions within the group. Students often asked the instructor to repeat the experiment because they did not believe the outcome was possible. Students were allowed to repeat the experiment themselves. Students continued to debate the reasons for predicting particular outcomes. The group would reach the correct physical interpretation of the observed phenomenon in collaboration with the teacher during the final discussion. During the execution of the experiment, the seating arrangement in the laboratory was informal. Students wanted to get as close to the site of performance, and they were allowed to carry out the experiment themselves.

During the active-learning classes, when students demonstrated a lack of understanding of certain topics, they tried to solve the problems through a process of recognition and discussion. Students were able to directly engage in learning by reacting to what they observed and offering their own answers and explanations, thus trying to improve their predictions. During the project, students

Table 2. Pharmacy Students Pretest Results on the Lawson Classroom Test of Scientific Reasoning by Academic Year

\begin{tabular}{|c|c|c|c|c|c|c|c|c|c|}
\hline \multirow[b]{2}{*}{ Lawson Classification } & \multicolumn{5}{|c|}{$\begin{array}{l}\text { Active-Learning Method Group } \\
\qquad(\mathrm{N}=90)\end{array}$} & \multicolumn{4}{|c|}{$\begin{array}{l}\text { Traditional Learning Method Group } \\
\qquad(\mathrm{N}=60)\end{array}$} \\
\hline & $2013 / 2014$ & $2014 / 2015$ & $2015 / 2016$ & $\Sigma$ & $\%$ & $2016 / 2017$ & $2017 / 2018$ & $\Sigma$ & $\%$ \\
\hline Transitional & 20 & 20 & 18 & 58 & $64.5^{\mathrm{a}}$ & 21 & 18 & 39 & 65.0 \\
\hline Formal & 4 & 4 & 5 & 13 & $14.4^{\mathrm{a}}$ & 3 & 5 & 8 & 13.3 \\
\hline
\end{tabular}

${ }^{a}$ Statistically no different from the traditional learning method group, $p>.05$ 


\section{American Journal of Pharmaceutical Education 2020; 84 (8) Article 7610.}

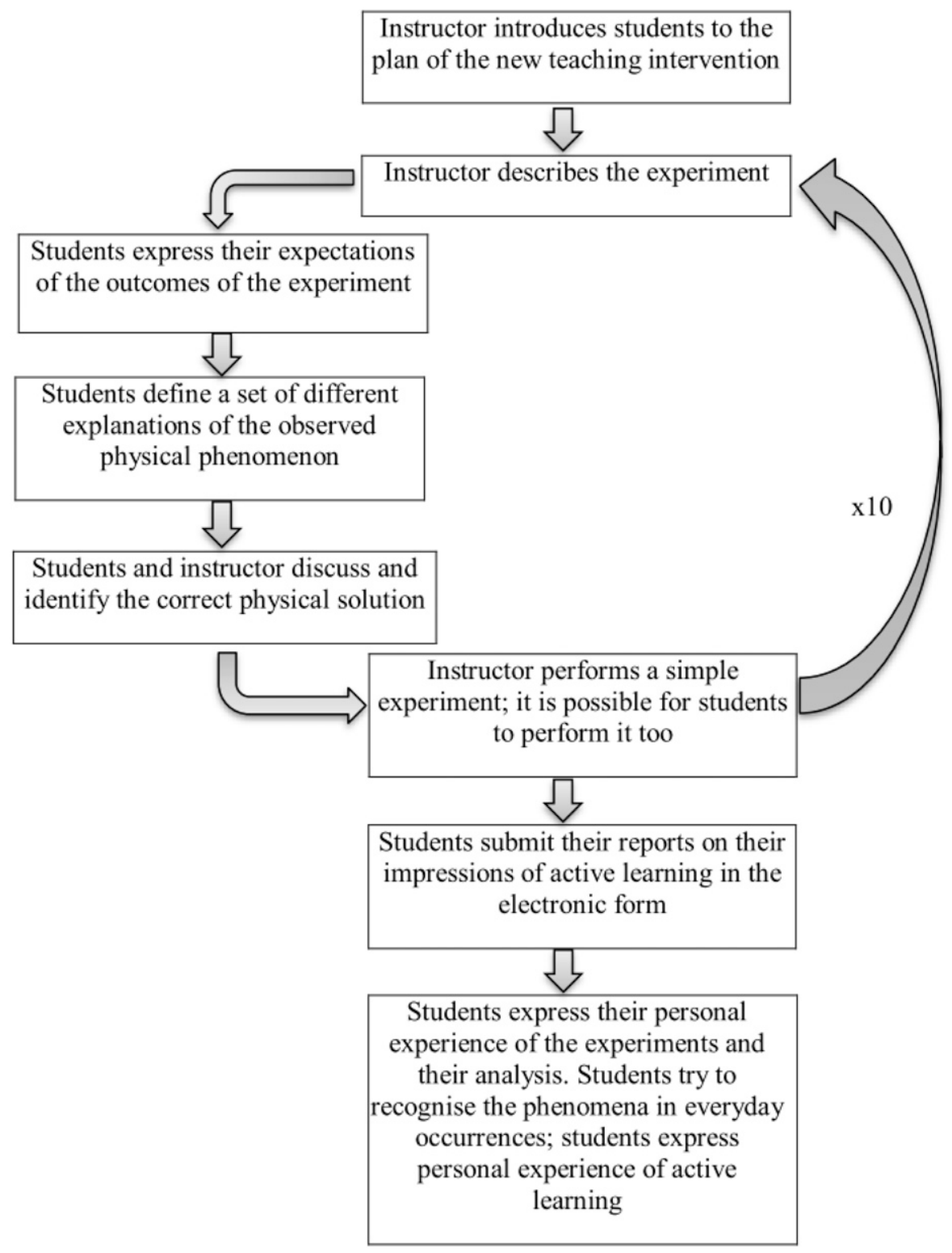

Figure 1. The Active Cycle of Active Learning of Physics Using Simple Experiments for One Group (10 Students)

participated in discussions, which enabled them to obtain new knowledge and recognize new concepts in out-ofclass situations. Appendix 2 shows two examples for each of the above-mentioned sequences of active learning.

To compare the active-learning methods (experimentation and discussion) with traditional methods, we assessed learning in the 60 students in the control group. Those students attended regular laboratory sessions that consisted of listening to traditional lectures, conducting measurements, and writing a laboratory report. The two groups were taught by the same instructor, but students in the traditional learning group were not exposed to the active-learning methods that were applied in the experimentation and discussion group.

\section{Measuring Instrument}

The instrument used for measuring gains in scientific reasoning ability in the two groups was Lawson's Classroom Test of Scientific Reasoning (LCTSR). ${ }^{26} \mathrm{We}$ applied it at the beginning and at the end of the project. The test consists of 24 questions. The questions refer to several areas: inferences about conservation, concluding about proportions, identification and control of variables, understanding probability and hypothetical - deductive reasoning. All of these areas can be used to determine the level of students' scientific reasoning. The questions in the LCTSR are grouped in such a way that the student scores one whole point only when the answers to both questions, ie, the outcome and the explanation for the 


\section{American Journal of Pharmaceutical Education 2020; 84 (8) Article 7610.}

Table 3. Comparison of Pharmacy Students' Results on the Lawson Classroom Test of Scientific Reasoning Between ActiveLearning and Traditional-Learning Groups

\begin{tabular}{llccc}
\hline & & & Lawson Classification (\%) \\
\cline { 3 - 5 } & & Concrete & Transitional & Formal \\
\hline Active-Learning Method Group (N=90) & Pretest & 21.1 & 64.5 & 14.4 \\
& Posttest & 12.2 & 54.5 & 33.3 \\
Traditional Learning Method Group (N=60) & Shift & $-8.9^{\mathrm{a}}$ & $-10.0^{\mathrm{a}}$ & $18.9^{\mathrm{a}}$ \\
& Pretest & 21.7 & 65.0 & 13.3 \\
& Posttest & 20,0 & 66.7 & 13.3 \\
& Shift & $-1.7^{\mathrm{b}}$ & $1.7^{\mathrm{b}}$ & 0.0 \\
\hline
\end{tabular}

${ }^{a}$ Significant shifts, $p<.05$

${ }^{\mathrm{b}}$ Non-significant shifts, $p>.05$

outcome, are consistent with formal operational reasoning.

The total possible score on the LCTSR is 12 and the following classification is given by Lawson ${ }^{27}: 0-4$ points $=$ empirical-inductive level (concrete-operational thinkers); 5-8 points $=$ transitional level (transitional thinkers); 9-12 points = hypothetical-deductive level (formaloperational thinkers). Considering the total score, the transitional level probably corresponds to Piaget's Early Formal and hypothetical-deductive to Piaget's Mature Formal. ${ }^{18}$

Data analysis was performed using SPSS Statistics, 22.0 (IBM, Armonk, NY). The Mann-Whitney U test was used to assess the possible statistical difference in LCTSR pre-test results for the experimentation and discussion group and traditional methods group. Wilcoxon signedrank test was used to determine statistical differences in the pre- to post- LCTSR results so we can evaluate how the differing teaching method of physics for experimentation and discussion group and the traditional methods group affects the change in the level of scientific reasoning. Both statistical tests are non-parametric tests, and the $p$ value was established at .05 a priori.

\section{RESULTS}

We analyzed students' pre-course results on the LCTSR on different levels of scientific reasoning by academic year. A small number of students in both the active-learning group and traditional learning methods group had already reached the level of formal thinking prior to the course. There were no significant differences in the results on the Lawson pretest $(p>.05)$ between the two observed groups.

The pre- and post-intervention LCTSR test results in terms of the Piagetian levels are presented in Table 3. The experimentation and discussion group had more success in reaching the formal-operational level of thinking in comparison to the traditional learning methods group. In the experimentation and discussion group, the proportion of students showing formal thinking skills almost doubled.

The pre- and post-test LCTSR scores for the experimentation and discussion group students show that, before the course, $21.1 \%$ of students were concrete thinkers, $64.5 \%$ were transitional thinkers, and $14.4 \%$ were formal thinkers. After the course, $12.2 \%$ of students were

Table 4. Comparison of Pharmacy Students' Migrations Between Different Levels of Scientific Reasoning After Completing Physics Course Using Active-Learning and Traditional-Learning Method

\begin{tabular}{|c|c|c|c|c|c|c|c|}
\hline \multicolumn{4}{|c|}{ Lawson Classification of Active-Learning Method Group } & \multicolumn{4}{|c|}{ Lawson Classification of Traditional Method Group } \\
\hline \multicolumn{2}{|l|}{ Pretest } & \multicolumn{2}{|c|}{ Posttest } & \multicolumn{2}{|c|}{ Pretest } & \multicolumn{2}{|c|}{ Posttest } \\
\hline & \multirow{3}{*}{19} & Concrete & 11 & & & Concrete & 12 \\
\hline & & Formal & $3^{\mathrm{a}}$ & & & Formal & 0 \\
\hline & & Concrete & 0 & & & Concrete & 0 \\
\hline \multirow[t]{2}{*}{ Transitional } & \multirow[t]{2}{*}{58} & Transitional & 44 & Transitional & 39 & Transitional & 39 \\
\hline & & Concrete & 0 & & & Concrete & 0 \\
\hline \multirow[t]{2}{*}{ Formal } & \multirow[t]{2}{*}{13} & Transitional & 0 & Formal & 8 & Transitional & 0 \\
\hline & & Formal & 13 & & & Formal & 8 \\
\hline
\end{tabular}

${ }^{a}$ Significant migrations, $p<.05$

${ }^{\mathrm{b}}$ Non-significant migrations, $p>.05$ 


\section{American Journal of Pharmaceutical Education 2020; 84 (8) Article 7610.}

Table 5. Pass Rate and Average Final Grade on the Course Physics for Pharmacists for Students Active-Learning Method Group vs Traditional-Learning Method Group

\begin{tabular}{llccc}
\hline & & $\begin{array}{c}\text { Students that Passed the Course in } \\
\text { the Same Academic Year }\end{array}$ & $\begin{array}{c}\text { Students that Passed the Course in } \\
\text { the Following Academic Year }\end{array}$ & $\begin{array}{c}\text { Average } \\
\text { Grade }\end{array}$ \\
\hline Active-Learning Method & $\mathrm{N}$ & 84 & 6 & $4.0^{\mathrm{a}}$ \\
Group & $\%$ & $93.3^{\mathrm{a}}$ & $6.7^{\mathrm{a}}$ & 2.8 \\
Traditional Learning Method & $\mathrm{N}$ & 43 & 17 & \\
Group & $\%$ & 71.7 & 28.3 & \\
\hline
\end{tabular}

${ }^{\mathrm{a}}$ Statistically different from traditional learning method group, $p<.05$

concrete thinkers, $54.5 \%$ were transitional thinkers, and $33.3 \%$ were formal thinkers. Thus, the thinking levels of students in the experimentation and discussion group substantially increased after participating in the activelearning course format, with the percentage of formal thinkers increasing from $14.4 \%$ to $33.3 \%$.

The pre and post-test LCTSR scores for students in the traditional method group showed that, before the course, $21.7 \%$ were concrete thinkers, $65.0 \%$ were transitional thinkers, and $13.3 \%$ were formal thinkers. After the course, $20.0 \%$ were concrete thinkers, $66.7 \%$ were transitional thinkers, and $13.3 \%$ were formal thinkers. The thinking levels of students in the traditional methods group were not affected, which makes the LCTSR results for the experimentation and discussion group especially significant.

The migrations between different levels of thinking for students in the two groups are presented in Table 4. Eleven of the concrete thinkers remained at that level, five of them shifted to the transitional level, and three of them shifted to the formal level; 44 of transitional thinkers remained at that level, while 14 of them advanced to the formal level; 13 of the formal thinkers remained at that level. The pre- to post-test changes in reasoning level for students in the traditional methods group were: 12 concrete thinkers remained at that level, while one shifted to the transitional level; 39 transitional thinkers remained at that level; and eight formal thinkers remained at that level (Table 4).

To evaluate the performance of using active-learning methods to teach physics, we also analyzed the pass rate and final examination scores of students in the Physics for Pharmacists course, and compared the results with those of students in the traditional methods group (Table 5). Students' passing rate was significantly better for students in the experimentation and discussion group (93.3\%) compared to students in the traditional methods group (71.7\%). Comparing students' grades on the final test of the Physics for Pharmacists course also shows that students in the active-learning group achieved a better mean grade point average $4.0(\mathrm{SD}=0.9)$ than students in the traditional learning group $2.8(\mathrm{SD}=0.9)$.
At the end of the course, the students that used activelearning methods (experimentation and discussion group) expressed their opinion in the form of a free essay. Their reports indicate a positive attitude towards all the main features of the new learning method: a deeper understanding of the physical laws, an active involvement through discussion and experimentation, and a change of the perception of physical laws applicable to common, real-life experiences.

\section{DISCUSSION}

Encouraged by the connection between teaching and learning methods and cognitive changes, we have studied gains in scientific reasoning in two distinct learning designs: traditional lecture methods vs experimenting and discussion of classic topics in physics. Therefore, we have considered the extent to which learning methods can have a positive effect on cognitive changes in pharmacy students. The results before testing show that less than $15 \%$ of the first-year pharmacy students study at the level of formal operational thinking. This certainly hampers a large number of students from learning abstract physics concepts and prevents high-quality learning of physics. Measuring student learning is a complicated but necessary task in order to understand the effectiveness of the teaching methods used. Traditionally accepted beliefs assume that physics lectures, which emphasize the logical and mathematical structures of physical concepts, improve students' scientific thinking. However, the insignificant gain among students in the traditional methods group suggests that these teaching methods produce no significant improvement in the average student's scientific reasoning ability. On the other hand, the experimentation and discussion methods used in active learning recognize the need to challenge students and stimulate higher levels of thinking.

The active-learning approach is becoming an expectation in both clinical practice and foundational science courses, Gleason et al. recognized the importance and the potential barriers of engaging students in the active learning process. $^{22}$ In this study, we faced the 


\section{American Journal of Pharmaceutical Education 2020; 84 (8) Article 7610.}

challenge of integrating active learning into a physics curriculum, but also of raising students' level of scientific reasoning with the active-learning method, which requires only a minimum knowledge of basic physics concepts. The increased level of scientific reasoning enabled the students to achieve better results on the Lawson Classroom Test of Scientific Reasoning and on the final test in the Physics for Pharmacists course. We believe that this shift in level of scientific reasoning achieved by simple experiments is not limited just to this course. By learning how to predict, observe, and explain, or how to observe, explain, predict, and test, students can use these elements of active learning in other foundational science courses and in their clinical practices.

Duda and Garrett state that an important goal of the physics curriculum is to leave students with a positive attitude toward physics, which is crucial for applying this science to other fields such as biology and pharmacy as well as in everyday life. ${ }^{28}$ For some students, abstract physics concepts are difficult to understand and can be intimidating. This research addresses these issues by implementing the experiments described above with a surprising outcome. The surprising outcome encourages students to think creatively and seek physical solutions for the observed effect. During the process, students interact with each other, often outside the physics laboratory. This may result in increased student interest in physics as well as science in general.

Ofstad and Brunner elaborate on the importance of team-based learning and point out the ability to communicate and work in a team-oriented environment as skills that pharmacists need to have developed by the time they enter the workplace. ${ }^{29}$ However, team-based learning can be challenging to implement into the physics course. By participating in the active-learning methods of experimentation and discussion, we wanted to put an emphasis on team-based learning and develop students' social and teamwork skills.

Previous research has emphasized the connection between successfully applying the concepts of evidencebased medicine and students' development of scientific reasoning ability. ${ }^{20}$ By elevating the level of scientific reasoning, critical thinking, and team-based learning, we wanted to establish a foundation for the use of evidencebased medicine during the physics course.

Redesigning a physics course to implement the active-learning method is challenging from a resource standpoint. We were keen on conducting a research study with minimal financial costs, with the idea of providing an efficient active-learning method that could easily be conducted, even with limited or no financial support.
This study has some limitations. While we have achieved significant shifts in the level of scientific reasoning, the same results are yet to be achieved by different instructors. Also, the duration of the physics course may be too short to fully instill a habit of using active-learning methods in students. Therefore, other instructors and courses may be needed to follow the same blueprint to achieve the full potential of the method.

\section{CONCLUSION}

The results here demonstrated that active-learning learning methods (ie, experimentation and discussion) applied in during a three-week interval in each academic year, achieved a significant improvement in students' level of scientific thinking as well as the transition of $28.6 \%$ of students to higher levels of scientific thinking. The active-learning group results are comparable to the results obtained in one of the best intervention programs in science education, cognitive acceleration. ${ }^{30}$

The experimentation and discussion methods used helped students to achieve better pass rates and mean scores in the Physics for Pharmacists course. By increasing their level of scientific thinking, we believe that students also built the foundation to master the use of evidence-based medicine. However, the potential weaknesses of this study should be considered. Additional research is needed to determine whether similar gains in students' level of scientific thinking would be achieved by other researchers who use active-learning methods, such as experimentation and discussion, in a physics course for pharmacy students.

\section{ACKNOWLEDGMENTS}

The authors wish to thank Mr. Denis Sablic, MA in finance for his editorial review of this manuscript.

\section{REFERENCES}

1. Giere RN, Bickle J, Mauldin RF. Understanding Scientific Reasoning. 5th edition. Belmont, CA: Thomson-Wadsworth Publishing; 2006.

2. Barz DL, Achimaş-Cadariu A. The development of scientific reasoning in medical education: a psychological perspective. Clujul Med. 2016;89(1):32-37.

3. Zimmerman C. The Development of Scientific Reasoning: What Psychologists Contribute to an Understanding of Elementary Science Learning. 2005.

4. Stevens SS, Wixted JT. Stevens' Handbook of Experimental Psychology and Cognitive Neuroscience. 4th edition. New York, NY: John Wiley \& Sons; 2018.

5. Kuhn TS. The Structure of Scientific Revolutions. 3rd edition. Chicago, IL: The University of Chicago Press; 1996.

6. Fetzer JH. Foundations of Philosophy of Science: Recent Developments. 1st edition. New York, NY: Paragon House; 1993. 


\section{American Journal of Pharmaceutical Education 2020; 84 (8) Article 7610.}

7. Glaze AL. Teaching and learning science in the 21 st century: challenging critical assumptions in post-secondary science. Educ Sci. 2018;8(1):1-8.

8. Coletta VP, Phillips JA, Steinert JJ. Why you should measure your students' reasoning ability. Phys Teach. 2007;45(4):235-238.

9. Quitadamo IJ, Kurtz MJ. Learning to improve: using writing to increase critical thinking performance in general education biology. CBE-Life Sci Educ. 2007;6(2):140-154.

10. Sun RCF, Hui EKP. Cognitive Competence as a Positive Youth Development Construct: A Conceptual Review. Sci World J. 2012; Article ID 210953.

11. Collins R. Skills for the 21st century: teaching higher-order thinking. Curriculum \& Leadership Journal. 2014;2(14).

12. Renner JW, Lawson AE. Promoting intellectual development through science teaching. Phys Teach. 1973;11(5):273-276.

13. Lawson AE. The generality of hypothetico-deductive reasoning: making scientific thinking explicit. Am Biol Teach.

2000;62(7):482-495.

14. Elkind D. Quality conceptions in college students. J Soc Psychol. 1962;57(2):459-465.

15. Towler JA, Wheatley GG. Conservation concepts in college students. J Genet Psychol. 1971;118(3):265-270.

16. Arons AB, Karplus R. Implications of accumulating data on levels of intellectual development. Am J Phys. 1976;44(4):396-396. 17. Maloney DP. Comparative reasoning abilities of college students. Am J Phys. 1981;49(8):784-786.

18. Shayer M, Wylam H. The distribution of Piagetian stages of thinking in British middle and secondary school children II: 14-16year olds and sex differentials. Brit J Educ Psychol. 1978;48:62-70. 19. Lom B. Classroom activities: simple strategies to incorporate student-centered activities within undergraduate science lectures. J Undergrad Neurosci Educ. 2012; 11(1):

A64-A71.

20. Vira P, Nazer L, Phung O, Jackevicius CA. A longitudinal evidence-based medicine curriculum and its impact on the attitudes and perceptions of student pharmacists. Am J Pharm Educ.

2019;83(1):Article 6510.

21. Lave J, Wenger E. Situated Learning: Legitimate Peripheral Participation. 1st edition. Cambridge, UK: Cambridge University Press; 1991.

22. Gleason BL, Peeters MJ, Resman-Targoff BH, et al. An activelearning strategies primer for achieving ability-based educational outcomes. Am J Pharm Educ. 2011;75(9):Article:186.

23. White R, Gunstone R. Probing Understanding. 1st edition. London, UK: The Falmer Press; 1992.

24. Van Heuvelen A, Etkina E. The Physics Active Learning Guide. Instructor Edition. San Francisco, CA: Addison Wewley; 2006.

25. Pfundt H, Duit R. Bibliography. Students Alternative

Frameworks and Science Education. 2nd edition. Kiel, DE: Institute for Science Education; 2006.

26. Lawson AE. Classroom Test of Scientific Reasoning. Revised pencil paper version. Tempe, AZ: Arizona State University; 1996. 27. Lawson AE. Science Teaching and the Development of Thinking. 1st edition. Belmont, CA: Wadsworth Publishing Company; 1995.

28. Duda G, Garrett K. Blogging in the physics classroom: a research-based approach to shaping students' attitudes toward physics. Am J Phys. 2008;76(11).

29. Ofstad W, Brunner LJ. Team-based learning in pharmacy education. Am J Pharm Educ. 2013;77(4):Article 70.

30. Leo EL, Galloway D. Conceptual links between cognitive acceleration through science education and motivational style: a critique of Adey and Shayer. Int J Sci Educ. 1996;18(1):35-49. 


\section{American Journal of Pharmaceutical Education 2020; 84 (8) Article 7610.}

Appendix 1. Description of the Simple Exercises Used in the Active Learning Method Group of Pharmacy Students as Part of a Study

\begin{tabular}{|c|c|c|}
\hline No. & Experiment & Description \\
\hline \multirow[t]{2}{*}{1} & Coin collision & $\begin{array}{l}\text { Collisions of } 5 \text { equal coins in different } \\
\text { combinations. The combinations in which } \\
\text { one of the coins is held by a finger are also } \\
\text { observed. }\end{array}$ \\
\hline & Inertia ring & $\begin{array}{l}\text { A cardboard ring is put on top of a bottle. A } \\
\text { small iron object is put on the ring. If you } \\
\text { suddenly pull the ring the object falls into the } \\
\text { bottle. }\end{array}$ \\
\hline 2 & Accelerometer & $\begin{array}{l}\text { Bottle corks are connected with a thread. One } \\
\text { tap is pushed in, then the bottle is filled with } \\
\text { water and closed with the other tap. Then the } \\
\text { bottle is turned neck down with the tap inside } \\
\text { tightening the thread in an effort to rise to the } \\
\text { surface. The inside tap is observed while the } \\
\text { bottle is moving at some acceleration. }\end{array}$ \\
\hline \multirow[t]{2}{*}{3} & Nails & $\begin{array}{l}11 \text { nails are put on top of one nail which is } \\
\text { nailed into a stand. }\end{array}$ \\
\hline & Strange balance & $\begin{array}{l}\text { A spoon and a fork are placed on a toothpick } \\
\text { and it is together placed on the edge of a glass } \\
\text { so that the system is balanced. Finally, both } \\
\text { ends of the toothpick are lit. }\end{array}$ \\
\hline \multirow[t]{4}{*}{4} & Plastic bottle (one hole - up - down) & $\begin{array}{l}\text { A hole is made on a plastic bottle. The bottle is } \\
\text { filled with water and the hole is kept closed. } \\
\text { We toss the bottle up and down. }\end{array}$ \\
\hline & A bottle and many holes & $\begin{array}{l}\text { A series of small holes is made on a bottle. The } \\
\text { bottle is filled with water and tapped. The } \\
\text { flow of water is controlled by turning the tap } \\
\text { on the bottle. }\end{array}$ \\
\hline & A bottle and a balloon & $\begin{array}{l}\text { A hole is made on a plastic bottle. A balloon is } \\
\text { put in the bottle. We try blowing the balloon } \\
\text { with the hole open and with the hole closed. }\end{array}$ \\
\hline & Horizontal projectile & $\begin{array}{l}\text { Three small holes are made on a plastic bottle } \\
\text { (at } 1 / 4,1 / 2 \text { and of the bottle length). The level } \\
\text { of water is kept stable. The jets from the holes } \\
\text { are observed. }\end{array}$ \\
\hline \multirow[t]{2}{*}{5} & Balloon filled with air and water & $\begin{array}{l}\text { A balloon is blown and placed above the open } \\
\text { flame. The balloon is filled with water and } \\
\text { placed above the open flame again. }\end{array}$ \\
\hline & Glass filled with water & $\begin{array}{l}\text { A paper cup is filled with a bit of water and } \\
\text { placed on the source of heat until the water } \\
\text { boils. }\end{array}$ \\
\hline 6 & Crushed tin & $\begin{array}{l}\text { Some water is poured into a tin and is heated. } \\
\text { After the water has boiled the tin is immersed } \\
\text { into a container filled with cold water, mouth } \\
\text { side down. }\end{array}$ \\
\hline 7 & Water in a bowl and a candle & $\begin{array}{l}\text { We pour about } 1 \mathrm{dl} \text { of colored water in a bowl } \\
\text { and we place a candle in the middle. We light } \\
\text { the candle and cover it with a glass. }\end{array}$ \\
\hline
\end{tabular}

(Continued) 


\section{American Journal of Pharmaceutical Education 2020; 84 (8) Article 7610.}

(Continued)

\begin{tabular}{|c|c|c|}
\hline No. & Experiment & Description \\
\hline \multirow[t]{2}{*}{8} & Bernoulli's principle & $\begin{array}{l}\text { Cardboards are cut into a rectangular shape and } \\
\text { are hung on two pens. Then we blow between } \\
\text { the cardboards. }\end{array}$ \\
\hline & Bernoulli's principle - Chimney & $\begin{array}{l}\text { A cardboard tube is placed above the bottom of } \\
\text { a glass in which there are pieces of paper. The } \\
\text { hairdryer blows horizontally in the upper end } \\
\text { of the tube. The aim is for the pieces of paper } \\
\text { to start flying out. }\end{array}$ \\
\hline \multirow[t]{2}{*}{9} & Sound - resonance, sound forks & $\begin{array}{l}\text { Two equal tuning forks with the corresponding } \\
\text { resonant boxes are placed on the table. We hit } \\
\text { the first fork. The other fork resonates. }\end{array}$ \\
\hline & Beats & $\begin{array}{l}\text { Two tuning forks slightly different in frequency } \\
\text { are made to flicker. They hear the sound } \\
\text { strikes. The sonic booms are heard. }\end{array}$ \\
\hline \multirow[t]{3}{*}{10} & Spinning plastic tube & $\begin{array}{l}\text { We spin a long plastic tube }(1.3 \mathrm{~m}) \text { producing } \\
\text { different harmonics. }\end{array}$ \\
\hline & Playing music on a glass & $\begin{array}{l}\text { By circling with the finger on the edge of a glass } \\
\text { we produce a sound. }\end{array}$ \\
\hline & Glass and a ping-pong ball & $\begin{array}{l}\text { We initiate flicker on a glass by circling motion. } \\
\text { We put the glass perpendicularly against the } \\
\text { wall and we throw a ping-pong ball inside. } \\
\text { After that we make the glass flicker. }\end{array}$ \\
\hline
\end{tabular}

Appendix 2. Description of the Types of the Sessions Used in the Active Learning Method Group of Pharmacy Students

\section{a. Predict-observe-explain: The smashed can experiment.}

The session commenced with the description of the experiment to be conducted. An empty soda can would be filled with water (about $0.3 \mathrm{dl}$ ). Then the can would be placed on a burner in order to bring the water to a boil. The water would be left to boil for 20-30 s, so that the interior of the can would be completely filled with hot steam.

In the meantime, while waiting for water to boil, a bowl with cold water would be prepared. Using a protective glove, the soda can would be taken from the burner and quickly dipped it into the cold water, upside down. The students had to predict: What will happen to the can when it is dipped into the cold water?

Most of the students predicted that, once the can was immersed into the cold water, it would slowly cool by letting the water slowly enter the can thus gaining thermodynamic balance. They compared it to throwing a hot stone or another solid body into the water, forgetting about the steam in the can.

Students knew from their personal experience that it takes a considerable force to smash a can. But when the experiment was conducted, the students saw, much to their surprise and amusement, the collapse of the can when it touched the cold water. The experiment was followed by students' explanation of the observed phenomenon. The instructor led the discussion using the following questions.

What force was responsible for the can collapse or deformation? What happened with the water in the can while it was getting hotter? What happens with steam when we dip the can in the cold water? What is the relationship between the pressure and temperature? What happens to the pressure in the can after the can is dipped into the cold water?

The students finally concluded that a sudden condensation of steam causes that pressure of the remaining steam to decrease dramatically (less steam-less pressure). This results in a difference between the inside and the outside pressure. This difference is large enough to smash the can.

\section{b. Observe-explain-predict-test: Air- and water-filled balloons over the candle flame.}

The session commenced by inflating a balloon with air. The students were asked what would happen if a candle flame was brought close to the surface of the balloon. Their daily experience with balloons suggests to them that the balloon will explode. The "observe" phase was carried out to confirm that their answer based on their experience is correct. They could see the result of the experiment: the 


\section{American Journal of Pharmaceutical Education 2020; 84 (8) Article 7610.}

candle flame burned a small hole in the balloon and the air quickly escaped with a burst. In the "explain" phase, the students were asked to explain what they observed.

After much discussion, the students developed this explanation: "The heat is quickly transferred into the balloon because the rubber is stretched thin. With air inside the balloon, this heat is not readily dissipated away from the spot touching the flame. That's why the balloon partially melts or burns, then quickly bursts."

In the next "predict" phase of the sequence, the balloon was filled with water and the students were asked to answer the question: What will happen if the candle flame is brought close to the surface of the balloon? Class discussion led to the prediction that the balloon would burst again because the rubber will again touch fire and it would burn letting the water leak from the balloon.

The experiment was conducted and students' reactions observed. The students were surprised with the outcome — the balloon did not burst.

The experiment allowed students to test their predictions and finally dismiss them, but also to conclude that water has a higher specific heat capacity than air. Since the students were familiar with the concept of heat capacity, the experiment provided the opportunity for them to test the previously acquired knowledge and visualize the extent to which the specific heat of water is much higher than the specific heat of air. Within this session the students were also able to test their ideas about the following problem: Can water reach the boiling point in a paper cup? This was a further simple example that enabled students to test their acquired knowledge. 